\title{
THE EFFECT OF AIR FOAM INCLUSION ON THE PERMEABILITY AND ABSORPTION PROPERTIES OF LIGHT WEIGHT SOIL
}

\author{
Yoshiaki Kikuchi ${ }^{i)}$, Takeshi Nagatome ${ }^{\text {ii) }}$, TAKa-AKi Mizutani ${ }^{\text {iii) }}$ and Hiroyuki Yoshino ${ }^{\text {iv) }}$
}

\begin{abstract}
Cement-treated clay with air foam, which is called Super Geo-Material (SGM), was developed to utilize dredged clay in an effective way. As SGM is mainly used at levels below the ground water table, water permeability and absorption properties of SGM will affect the durability of the material. In this research, the changes in SGM permeability and absorption as functions of the air foam fraction were investigated. First, permeability tests with triaxial apparatus and constant rate of consolidation tests were conducted on samples containing less than $10 \%$ of air foam by volume. From the results, air foam was found to be an impermeable medium in SGM. Secondly, a series of permeability tests and absorption tests were conducted for the SGM with different fractions of air foam while observing the specimen with a micro focus X-ray Computed Tomography (CT) scanner. The results showed that the permeability of SGM increased dramatically due to the appearance of interior water channels when the air foam fraction exceeded $30 \%$ by volume. The density distribution change and water absorbed zones of the specimens during absorption tests were estimated using the X-ray CT data. From these results, the air in the SGM was found to be progressively substituted with water from the surface to the inside of the specimen and the substituted zone expanded as it made its way to the specimen interior. The expansion velocity of the substituted zone was not affected by the coefficient of permeability but by the fraction of the air in the specimen.
\end{abstract}

Key words: absorption, light weight soil with air foam, micro focus X-ray CT scanner, permeability, visualization (IGC: D10)

\section{INTRODUCTION}

The reuse of industrial by-product has been a subject of increasing focus in Japan during the past decade. Among the types of by-products, dredged soil, fly ash, and granulated blast furnace slag have been the most promising materials for reuse, and have been substituted for geo-materials for port construction. Effective use of dredged clay is one of the most important issues for port construction engineers, because maintaining navigation channels and basins produce large amounts of the material. Dredged clay has been used for reclamation material for many years, but this represents only passive utilization. A more active utilization method for dredged clay is highly desirable.

Super Geo-Material (SGM) was developed to achieve such active utilization of dredged clay (Tsuchida et al., 1996). This material is made by mixing dredged slurry with cement and introducing air foam or expanded polystyrofoam beads (EPS) at the construction site using a mixing plant. The main purposes of using this material to reduce the earth pressure on a retaining wall or the set- tling of the reclaimed field. To perform these purposes, dredged clay was converted to a high strength material by adding a cementing component, and was made to be a light weight material through the addition of a low-density filler. In this research air foam was considered as the light weight filler material.

Waterfront construction is a typical application for SGM. The characteristics of this material can be influenced by seawater when it is used in coastal areas. There is a risk that some air in the SGM may be replaced with water over time. The factors in this problem include not only water pressure but also the permeability and absorption properties of SGM. Material strength may also be reduced by contact with seawater and groundwater pollution through the release of alkaline material may also occur. These phenomena are affected by the permeability and absorption properties of the material.

The objective of this study is to evaluate the permeability and absorption properties of light weight soil containing air foam by the results of nondestructive testing using a micro focus X-ray Computed Tomography (CT) scanner. As a first step, permeability tests with a triaxial ap-

i) Director, Geotechnical and Structural Engineering Department, Port and Airport Research Institute, Kanagawa, Japan.

ii) Senior Researcher, Geotechnical and Disaster Prevention Technology Group, Toa Corporation, Kanagawa, Japan.

iii) Senior Researcher, Geotechnical and Structural Engineering Department, Port and Airport Research Institute, Kanagawa, Japan.

iv) Senior Engineer, Engineering Management and Coordination Division, Yachiyo Engineering Company, Kanagawa, Japan.

The manuscript for this paper was received for review on January 7, 2009; approved on October 1, 2010.

Written discussions on this paper should be submitted before September 1, 2011 to the Japanese Geotechnical Society, 4-38-2, Sengoku, Bunkyo-ku, Tokyo 112-0011, Japan. Upon request the closing date may be extended one month. 
paratus and constant rate of consolidation tests were performed. From the results, a hypothesis of the hydraulic conductivity mechanism was formulated. The first series of permeability tests were conducted using only one mixing condition. The second series of permeability tests and absorption tests were conducted on specimens of light weight soil with different volume ratios of air foam. Permeation and absorption states during these tests were observed by the micro focus X-ray CT scanner. As the CT scan can detect the density structure of the object and the density of the SGM will be changed by the substitution of air to water, the density distribution change and water absorbed zones of the specimens were estimated using the $\mathrm{X}$-ray CT data. According to these results, the effects of the air foam ratio on the permeability and absorption characteristics of light weight soil were evaluated.

\section{PREVIOUS STUDY}

In general, the coefficient of permeability of the soils treated with cement tends to decrease from that of the original soil. The change in the permeability coefficient of cement-treated soil is affected by cement volume, water volume and curing time, as shown in Figs. 1 and 2 (Terashi et al., 1983). With increasing cement content and longer curing time, the compressive strength of cementtreated soil increases. Terashi et al. (1983) concluded that the coefficient of permeability of cement-treated soil was negatively correlated with compressive strength.

Mori et al. (1994) conducted a series of permeability experiments on cement-treated clay that contained air foam. The authors found that the permeability of this material was not affected by hydraulic gradient when the latter was in the range from 6 to 20, and that the permeability coefficient of cement-treated clay with air foam decreased as air volume increased. But these phenomena were not clarified with a quantitative discussion.

In Japan, the X-ray CT scanner has been used for geotechnical engineering experiments in the 1990s. For example, strike-slip fault model tests were conducted with a medical X-ray CT scanner (Tani and Ueda, 1993; Tani and Oyama, 2004). The shapes, sizes and development processes of shear bands forming typical structures have been investigated in prior studies.

The engineering properties of SGM were investigated using an industrial X-ray CT scanner (Otani et al., 2002a; Otani et al., 2002b). The physical, mechanical, absorption and drying properties of SGM were observed using the CT scanner, and scanner data were used to examine the distributions of the density and air foams in the SGM during each test.

\section{MICRO FOCUS X-RAY CT SCANNER USED IN THIS STUDY}

The X-ray CT scanner, which is used in medical diagnosis, has also been used for engineering purposes as a nondestructive testing method (Otani and Obara, 2004;

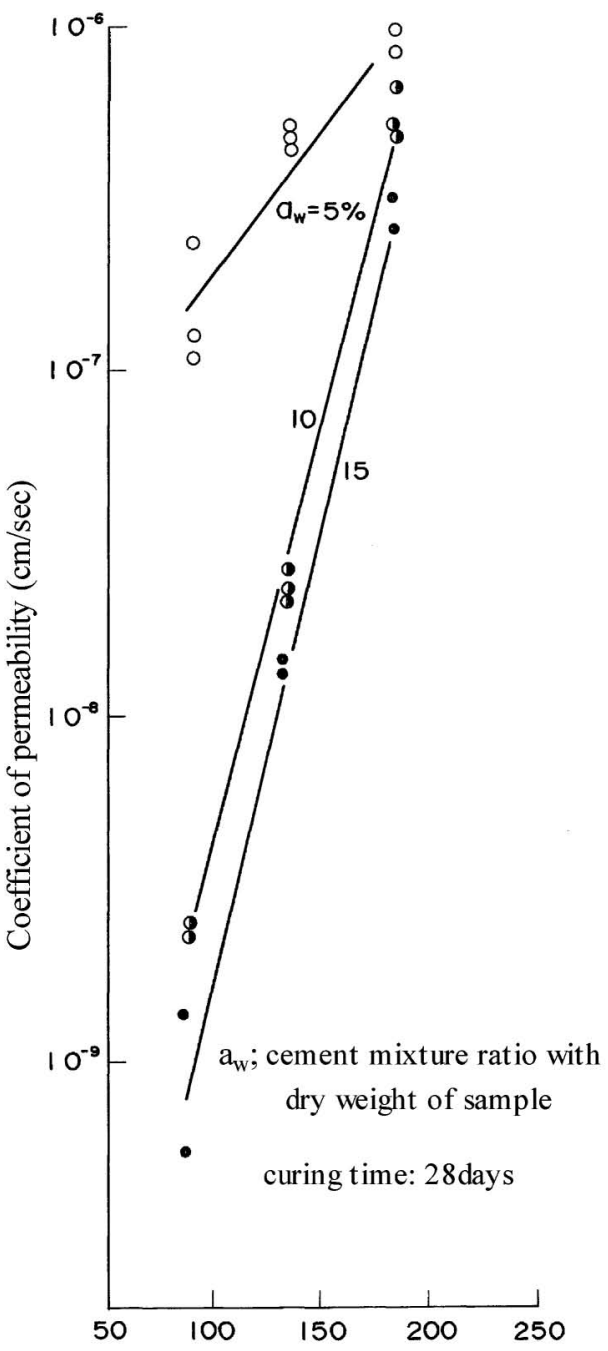

Water content ratio after mixing cement $(\%)$

Fig. 1. Relationships between the coefficient of permeability and water content ratio after mixing cement (Terashi et al., 1983)

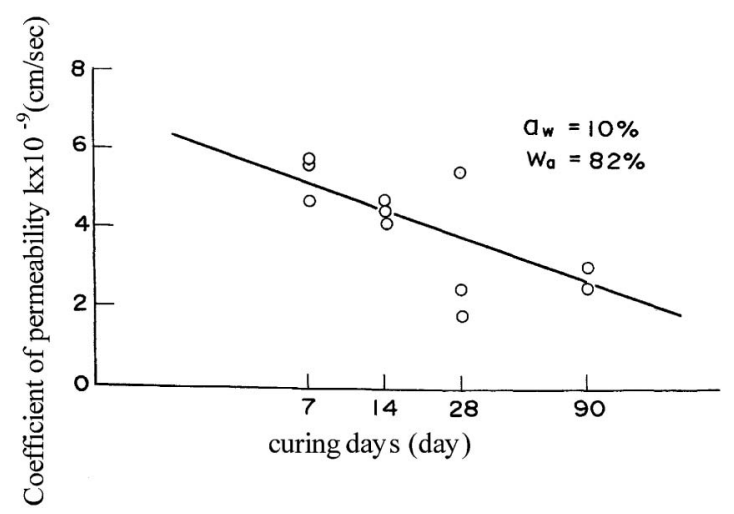

Fig. 2. Relationship between the coefficient of permeability and curing days (Terashi et al., 1983)

Desrues et al., 2006; Kikuchi, 2006), and a micro focus Xray CT scanner (SMX-225CT) was installed at the Port and Airport Research Institute in 2004 (Kikuchi et al., 2006). Clays are usually considered unsuitable for obser- 
Table 1. Specification of micro focus X-ray CT scanner in PARI

\begin{tabular}{|c|c|c|}
\hline \multirow{6}{*}{$\mathrm{X}$-ray unit } & Type & Non-enclosure \\
\hline & X-ray tube voltage & $30-225 \mathrm{kV}$ \\
\hline & $\mathrm{X}$-ray tube current & $10-1000 \mu \mathrm{A}$ \\
\hline & Maximum output & $135 \mathrm{~W}$ \\
\hline & minimum focus size & $4 \mu \mathrm{m}$ \\
\hline & X-ray irradiation angle & $60 \mathrm{deg}$. in cone shape \\
\hline $\begin{array}{l}\text { Image } \\
\text { intensifier }\end{array}$ & $\begin{array}{l}\text { Field-of-view diameter } \\
\text { for input window }\end{array}$ & $\begin{array}{l}9 / 7.5 / 6 / 4.5 \text { inches } \\
\text { (selectable) }\end{array}$ \\
\hline \multirow{2}{*}{ Test samples } & $\begin{array}{l}\text { Maximum mounting } \\
\text { dimensions }\end{array}$ & $\phi 250 \times 800 \mathrm{~mm}$ \\
\hline & Maximum weight & $600 \mathrm{~N}$ \\
\hline \multirow{2}{*}{$\begin{array}{l}\text { X-ray shield } \\
\text { box }\end{array}$} & Dimensions & $2150 \times 1310 \times 2400 \mathrm{~mm}$ \\
\hline & Weight & $45100 \mathrm{~N}$ \\
\hline
\end{tabular}

vation of inner density structure by X-ray CT scanners, because clay particles are too small and specimens made of clay are too homogeneous. But artificially mixed light weight materials based on clay are inhomogeneous in density. This kind of material is suited to density observations by a CT scanner, which may be used to analyze density changes.

X-ray CT scanner used in this study is a kind of micro focus type. The basic specification of this apparatus is shown in Table 1. The voltage and current of X-ray tube can be changed in this apparatus. Also the distances between X-ray tube and testing subject or image intensifier can be varied in this apparatus. These features make the micro focus X-ray CT scanner a large flexibility and it has great possibility for scanning wide variety of specimen. Very small focus performs a high level of resolution and it makes small part be easily observed. Maximum enlargement ratio is about eighty in this apparatus. To get more precise data, 6000 views can be taken in a full scan of the specimen for one cross section. The other feature is that 3D cone-beam imaging is applicable. By using 3D cone-beam imaging, it is possible to obtain consecutive images of specified cross sections. The maximum number of the scanning sections at a time is about 1000, although in usual scanning method one section can be scanned at a time. The resolution of CT image by this method drops a little, but it shortens the scanning time and it is still acceptable for our aim of analysis.

Figure 3 shows the overview of the apparatus. The shield box of this apparatus is designed for performing triaxial experiments in the box, so that water tubes, air tubes and electric cables are inserted from outside, and object mounting table can be moved about $80 \mathrm{~cm}$ for vertical direction.

CT image data are evaluated quantitatively using the so-called "gray level," which is expressed in a numerical number and proportional to the material density. It should be noted that if the voltage, current and cross sectional area is different, the gray level will also be different even with the same density sample. Figure 4 shows the
X-ray shield box $(2,150 \times 1,310 \times 2,400 \mathrm{~mm})$

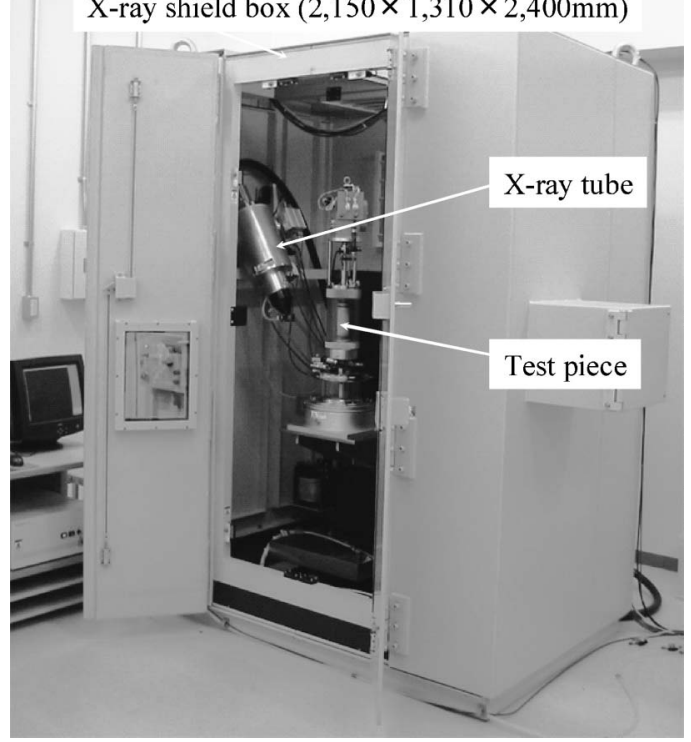

Fig. 3. Overview of micro focus $\mathrm{X}$-ray CT scanner in PARI

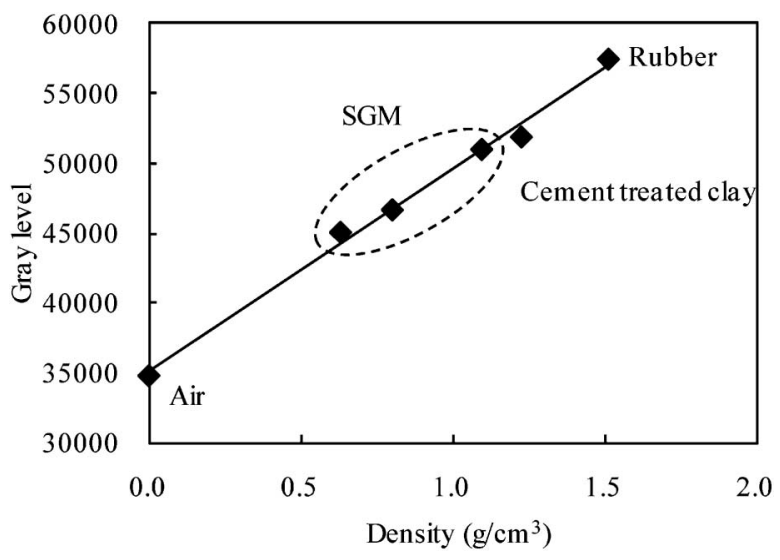

Fig. 4. Relationship between the gray level and wet density

relationship between the average gray level and average density of the test results under the same condition. These results show a linear relationship, which means that the gray level can be used as a parameter for evaluating density distribution. In other words, the "gray level" method enables a quantitative examination of material structural features based on this relationship with CT data. Based on the results, a quantitative discussion of density changes in soil under compression is also available.

By using 3D-cone beam imaging, gray levels are affected by the boundary condition, because the extinct difference of the density gives error of the analyzed gray levels. Figure 5 shows a vertical gray level distribution of a homogeneous rubber dummy specimen $(\phi 50 \mathrm{~mm} \times \mathrm{h} 100$ $\mathrm{mm}$ ) on the object mounting table with the cone-beam scanning. Each gray level shown in the figure is the average gray level of each height. Figure 6 shows the vertical gray level distribution of the dummy in the triaxial test apparatus shown in Fig. 7. Figures 5 and 6 show the 


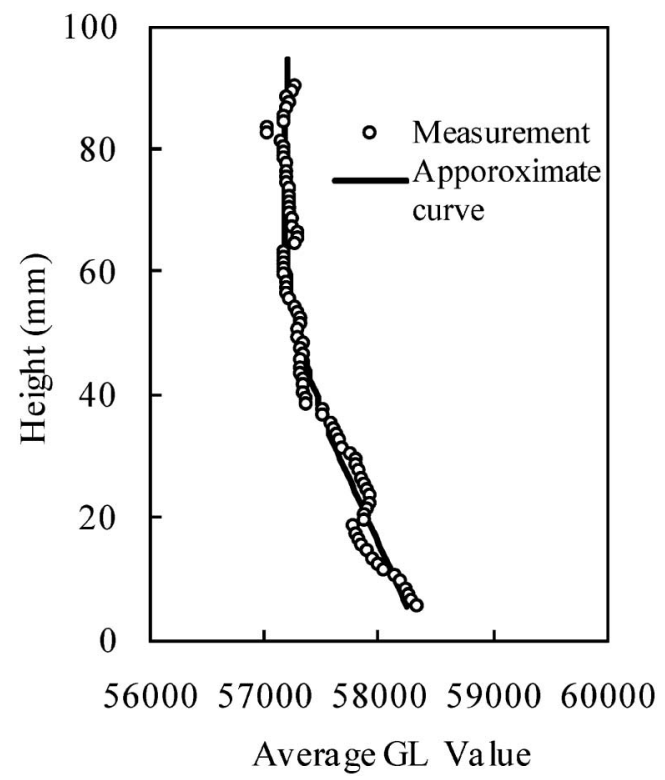

Fig. 5. Gray level distribution in a condition of the specimen on the table

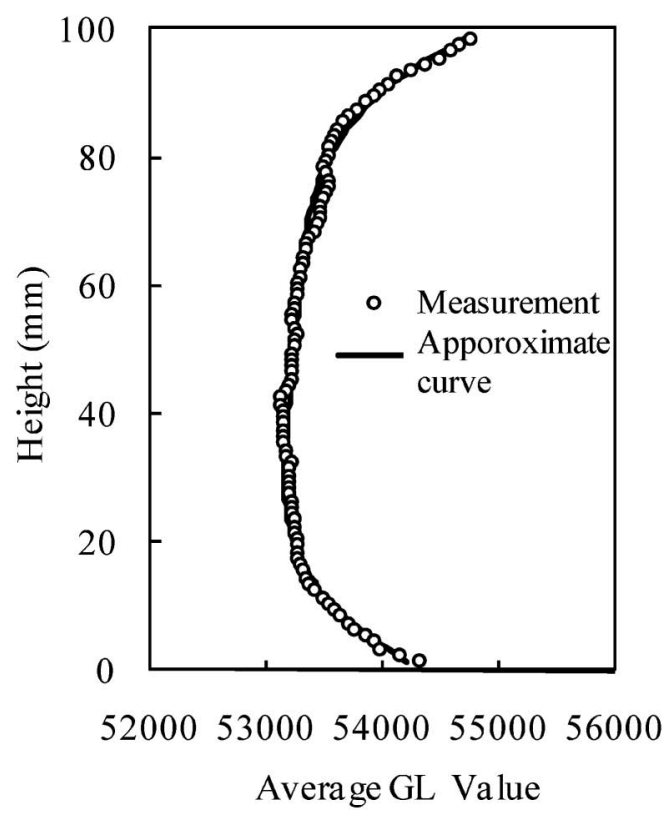

Fig. 6. Gray level distribution in a condition of the specimen in a triaxial cell

scanned results of the same specimen. Both the appearance of the gray level distribution and the level of values are different. This difference is due to the effect of the boundary of the specimen and the use of a cone-beam. Here, correction is made for each scanning condition in order to use the gray level in quantity parameters. The correction procedure is as follows; 1) Select a specimen with homogeneous density. A rubber dummy was selected in this case. 2) Select the scanning conditions as current and voltage applied to X-ray tube and the mounting condition of the specimen. 3) Scan the specimen with a cone-beam type scanning method. 4) Decide an approxi-

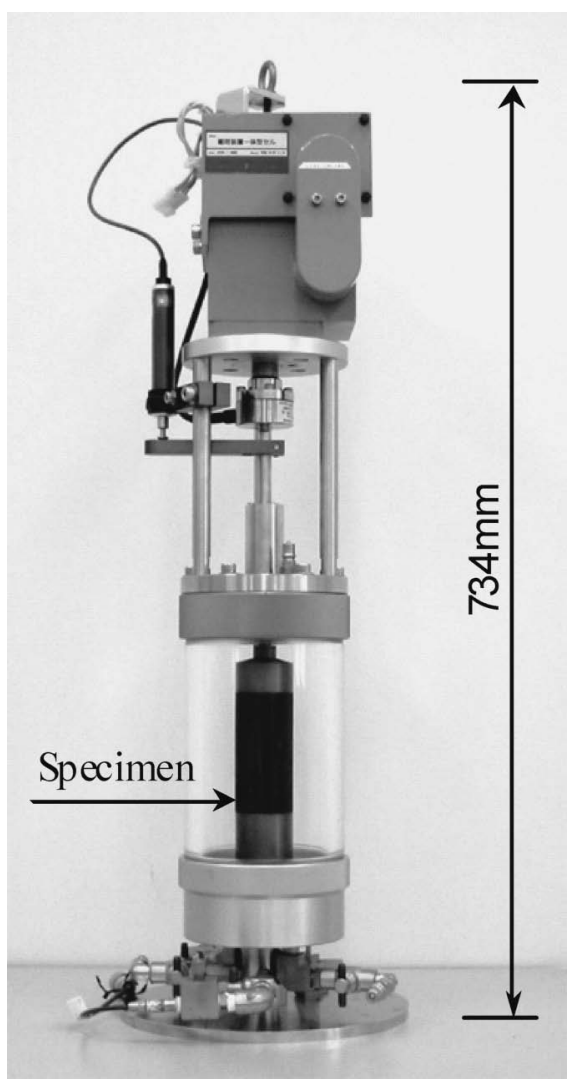

Fig. 7. Triaxial apparatus used in this study

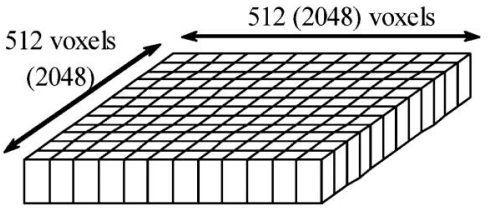

(a) X-ray CT image

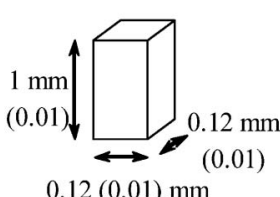

(b) Voxel
Fig. 8. Illustration of an X-ray CT image

mate curve of the vertical distribution of the average gray level in each height. 5) Decide the correction factors for each height. As the most precise gray level is given in a cross section which is horizontally radiated, the standard gray level is selected in such a cross section. Cross sections other than this plane were corrected with the correction factors which are decided approximated curve in the procedure 4.

An illustration of an X-ray CT image of the object with CT scanning is shown in Fig. 8. The voxel (volumetric pixel) size can be changed as required for the purpose. For example, in this study, the scanning space was divided into $512 \times 512$ or $2048 \times 2048$ voxels. In scans of the entire cross section of specimens, $512 \times 512$ voxels were used, and the size of one voxel was $0.12 \mathrm{~mm} \times 0.12 \mathrm{~mm} \times$ $1 \mathrm{~mm}$. Microscopic scans of the cross section were performed using $2048 \times 2048$ voxels, giving a voxel size of $0.01 \mathrm{~mm} \times 0.01 \mathrm{~mm} \times 0.01 \mathrm{~mm}$. Three-dimensional images are reconstructed by superposing two-dimensional 
Table 2. Mixing condition for CTC and SGM

\begin{tabular}{c|c|c|c|c}
\hline \multirow{2}{*}{ Target density } & \multicolumn{2}{|c|}{ CTC (air 0\%) } & \multicolumn{2}{c}{ SGM (air 24\%) } \\
\cline { 2 - 5 } & $\begin{array}{c}\text { Mass } \\
\left(\mathrm{kg} / \mathrm{m}^{3}\right)\end{array}$ & $\begin{array}{c}\text { Volume } \\
\left(\mathrm{L} / \mathrm{m}^{3}\right)\end{array}$ & $\begin{array}{c}\text { Mass } \\
\left(\mathrm{kg} / \mathrm{m}^{3}\right)\end{array}$ & $\begin{array}{c}\text { Volume } \\
\left(\mathrm{L} / \mathrm{m}^{3}\right)\end{array}$ \\
\hline Dry mass & 578 & 216 & 442 & 165 \\
\hline Water & 751 & 751 & 573 & 573 \\
\hline Cement & 101 & 33 & 75 & 25 \\
\hline Air foam & - & - & 10 & 237 \\
\hline Total & 1430 & 1000 & 1100 & 1000 \\
\hline
\end{tabular}

images.

\section{PERMEABILITY EXPERIMENT}

\section{Specimens}

In this series of tests, specimens of cement treated clay (CTC) and cement treated clay with air foam (SGM) were prepared. The dredged clay used in this series of tests was Kawasaki clay $\left(\rho_{\mathrm{s}}=2.678 \mathrm{~g} / \mathrm{cm}^{3}, w_{\mathrm{L}}=52.1 \%, I_{\mathrm{p}}=29.1\right)$. Cement was blast furnace slag cement $\mathrm{B}$, the particle density of which was $3.05 \mathrm{~g} / \mathrm{cm}^{3}$. Air foam was made of surfactant.

CTC and SGM were made by mixing four materials in a designed mixing condition as shown in Table 2. The target unconfined compressive strength of SGM at 28 days of curing time $q_{\mathrm{u} 28}$ was $200 \mathrm{kN} / \mathrm{m}^{2}$.

Moulds of $5 \mathrm{~cm}$ in diameter and $12 \mathrm{~cm}$ in height were filled up with the mixture and were sealed. These moulds were placed in a closed box of tap water in which the temperature was maintained at $20^{\circ} \mathrm{C}$ for about 28 days.

\section{Experimental Procedure}

Two types of permeability experiments were conducted. The first type was a series of permeability experiments using triaxial apparatus. The second was a series of constant rate consolidation tests performed to estimate the permeability of the materials (Kikuchi and Yoshino, 1998).

The procedure of permeability tests using the triaxial apparatus was as follows: First, the specimen was trimmed to $\phi 50 \mathrm{~mm} \times \mathrm{h} 100 \mathrm{~mm}$ and was placed in the triaxial cell. A cell pressure of $50 \mathrm{kPa}$ was then applied to initiate consolidation. In this time, no back pressure was applied. The consolidation period was 3 days. Following consolidation, a pressure of $20 \mathrm{kPa}$ was applied to the volume change burette connected to the bottom of the specimen to introduce water into the specimen from the bottom. The influent and effluent water volumes were measured using volume change burettes connected to the bottom and top of the specimen during the water flow. Water flow was continued till the influent and effluent water volumes were $15 \mathrm{~cm}^{3}$. The permeability of a specimen of cement treated clay, CTC, was also measured in order to investigate the effect of the air foam.

The mixing conditions of the SGM used in constant rate consolidation tests were the same as those used in the

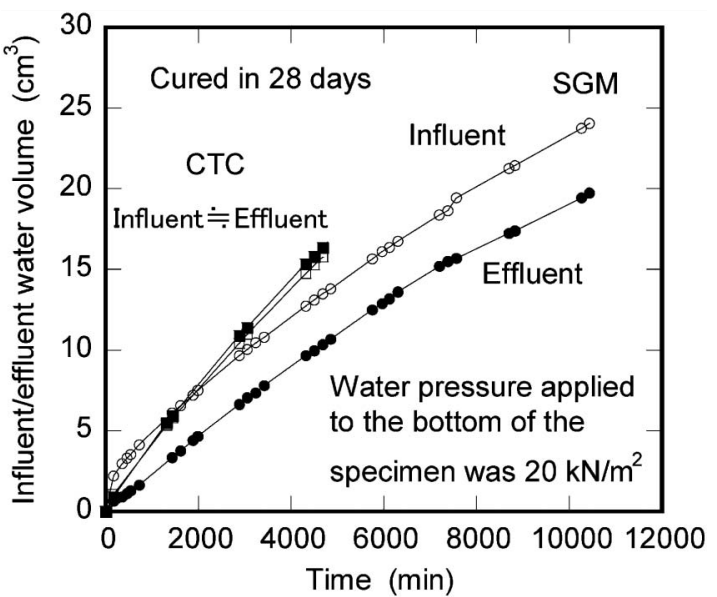

Fig. 9. Difference in influent/effluent water volume due to existence of air foam

triaxial permeability tests. The SGM was filled into a consolidation ring $\phi 6 \mathrm{~cm} \times \mathrm{h} 2 \mathrm{~cm}$. The specimen used in this test was cured for 28 days. After curing, the specimen was placed in the consolidation apparatus. A back pressure of $100 \mathrm{kPa}$ was applied to measure the pore water pressure change. The consolidation rate was $0.05 \% / \mathrm{min}$.

Figure 9 shows the relationship between time and the influent/effluent water volume in the triaxial permeability tests. Each specimen's water content ratio, which was defined as the ratio of mass of water to mass of both clay and cement, was substantially the same. The water pressure gradients were approximately 20 in both tests.

Figure 9 shows that when the specimen did not include air foam (CTC), the influent and effluent water volumes were virtually the same, and the influent and effluent velocities were basically constant. On the other hand, when the specimen included air foam (SGM), the velocity of the influent water was very fast and the water content increased initially, but then became constant. The water effluent rate of SGM was smaller than that of CTC. These two test results showed that the permeability determined from the effluent water volumes, that is "apparent" permeability, was larger without air foam than with air foam. This shows that air foam is a less permeable medium than the basic mixture of clay and cement.

The coefficient of permeability can be calculated from the following equation for the saturated soil in constant rate of consolidation tests.

$$
k=\frac{\Delta H \cdot \bar{H}}{2 \cdot \bar{u} \cdot \Delta t} \times \rho_{\mathrm{w}} \cdot g
$$

where $k$ : coefficient of permeability, $\Delta t$ : interval time, $\bar{u}$ : average pore pressure during interval time, $\bar{H}$ : average height of specimen during interval time, $\Delta H$ : amount of compression of specimen during interval time, $\rho_{\mathrm{w}}$ : density of water, $g$ : gravitational acceleration.

Figure 10 shows the relationship between coefficient of permeability and average void ratio of SGM derived from the result of constant strain rate consolidation tests.

Equation (1) ignores the compressibility of pore fluid. 


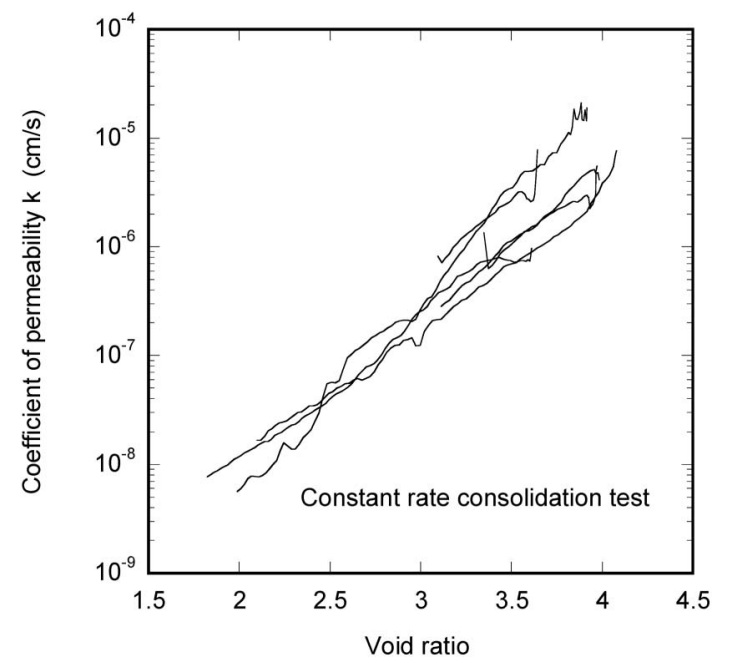

Fig. 10. Relationship between coefficient of permeability and average void ratio of SGM

But the SGM has air foams. The volume of air will be changed by the change of the pore pressure. It means pore fluid is compressible in SGM. This compressibility should be considered to calculate the coefficient of the permeability of SGM.

The consolidation of soil containing compressive fluid is expressed as follows:

$$
\alpha \cdot \frac{\partial u}{\partial t}=\frac{k}{m_{\mathrm{v}} \rho g} \frac{\partial^{2} u}{\partial z^{2}}
$$

where $\alpha=1+n\left(C_{\mathrm{w}}^{\prime} / m_{\mathrm{v}}\right), \rho$ : density of pore fluid, $z$ : distance, $t$ : time, $n$ : porosity $(=e /(1+e)), u$ : absolute pressure of pore fluid, $C_{\mathrm{w}}^{\prime}$ : volumetric compressibility of pore fluid $\left(=\left(1-S_{\mathrm{r}}\right) / u+S_{\mathrm{r}} C_{\mathrm{w}}\right)$ (Verruijt, 1969), $m_{\mathrm{v}}$ : coefficient of volume change for saturated soil, $C_{\mathrm{w}}$ : compressibility of water, $S_{\mathrm{r}}$ : degree of saturation.

Equation (2) is valid if the entrapped air is in a bubble state in the pore water and the coefficient of permeability is approximately the same as that of the saturated clay (Zen, 1993). Considering specimen preparation, the air in the SGM used here exists separately and does not pass through the specimen. It is therefore reasonable to treat the SGM as a material containing a compressible fluid when considering the permeability of SGM.

Figure 11 shows the difference of the calculated coefficient of permeability by Eqs. (1) and (2). Solid line shows the coefficient of permeability calculated by Eq. (1) and dotted line shows that calculated by Eq. (2). Figure 11 shows the effect of compressibility on the coefficient of permeability is large in the early stage of consolidation, but the effect gets smaller after the consolidation progressed.

In Fig. 11, the coefficients of permeability of CTC and SGM measured by the triaxial experiments were also plotted. The coefficients of permeability of SGM plotted in Fig. 11 were apparent values.

If the air foam is impermeable medium, the effective cross section for the permeation should be excluded from the cross section of the air foam. In accordance with this

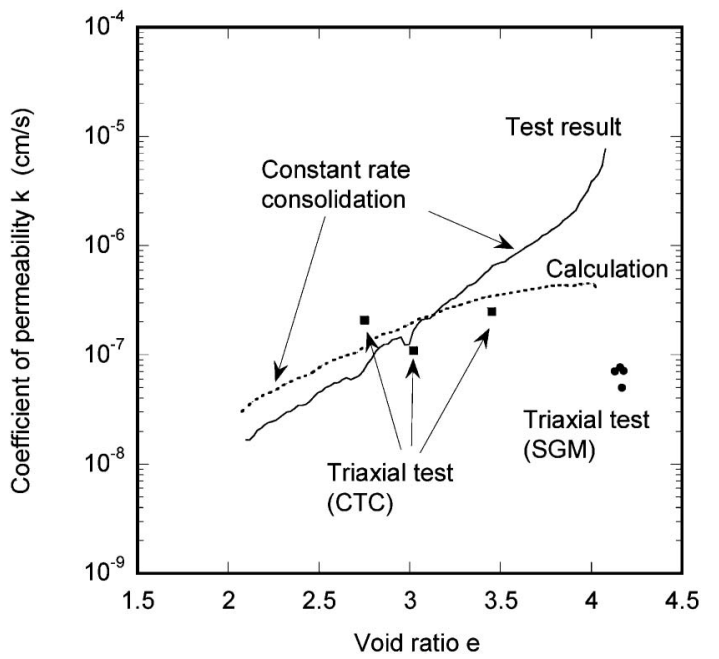

Fig. 11. Relationship between coefficient of permeability and void ratio (before correction)

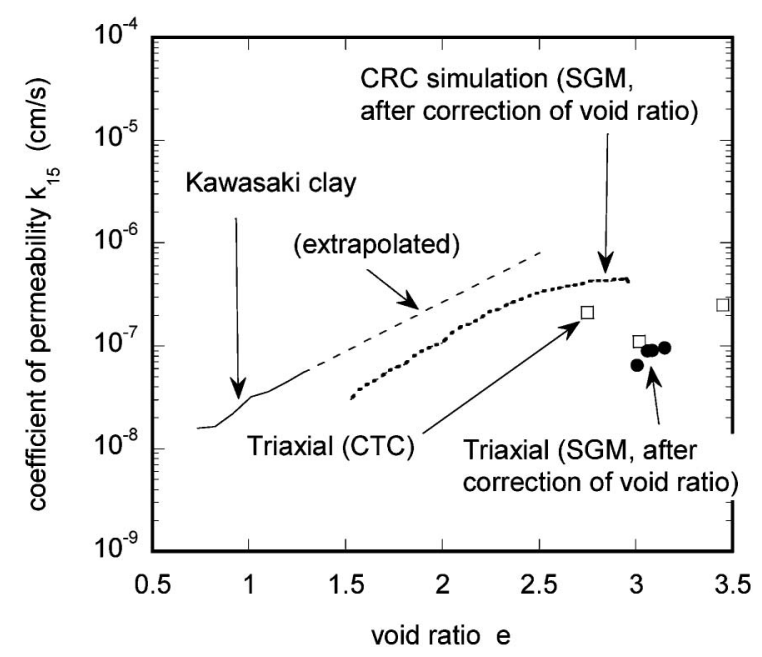

Fig. 12. Relationship between coefficient of permeability and void ratio (after correction)

consideration, the coefficient of permeability shown in Fig. 12 was calculated from $Q=k \cdot i \cdot A^{\prime}$; where $A^{\prime}=A_{0}-$ $A_{\text {a }}, A_{0}$ was the total cross area, $A_{\text {a }}$ was the cross area occupied by air foam. The coefficient of permeability calculated from this equation was called the corrected coefficient of permeability. Figure 12 shows the relationship between the corrected coefficient of permeability and the void ratio. In this figure, the void ratio was calculated excluding the air volume. This void ratio was considered to be the effective void ratio if the air foam is impermeable media.

Figure 12 shows that the relationship between the corrected coefficient of permeability and the effective void ratio of SGM and CTC estimated by the triaxial apparatus test are in good agreement. This result indicates that this kind of correction can represent the permeability of SGM from the macro viewpoint.

Figure 12 also shows the relationship between the permeability and void ratio of the Kawasaki clay used in 
the SGM. The permeability of Kawasaki clay is extrapolated in the figure because a linear relationship exists between the logarithm of permeability and the void ratio (Kobayashi et al., 1990). The corrected relationship of coefficient of permeability and void ratio of SGM estimated by the constant rate consolidation test was basically parallel to the coefficient of permeability and void ratio relationship of Kawasaki clay. Furthermore, from the relationship in the SGM shown in Fig. 12, the permeability of the SGM is rather small due to inclusion of cement in the mixture. The results in the present study showed that the reduction of permeability ranges from $1 / 30$ to $1 / 4$. These results agree with the results reported by Terashi et al. (1983).

From the above experimental results, the air foam included in the SGM was considered to be an impermeable medium.

\section{PERMEABILITY TEST WITH X-RAY CT SCANNER}

\section{Specimens}

The dredged clay used in the SGM in this series of experiments was Tokyo Bay clay $\left(\rho_{\mathrm{s}}=2.758 \mathrm{~g} / \mathrm{cm}^{3}, w_{\mathrm{L}}=\right.$ $\left.104 \%, I_{\mathrm{p}}=44\right)$. The cement and the surfactant used in this series were the same material used in the previous series of permeability experiments.

SGM was made by mixing four materials in a designed mixing condition as shown in Table 3 . The composition volume of air foam was $0,13,38$ and $59 \%$ with $1.25,1.1$, 0.8 and $0.6 \mathrm{~g} / \mathrm{cm}^{3}$ target densities, respectively. Here, the composition without air foam was cement treated clay (CTC). These mixing conditions were designed to have the same strength, $q_{\mathrm{u} 28}, 400 \mathrm{kPa}$, and fluidity of $180 \mathrm{~mm}$, as each other. Changing the water content ratio and the cement fraction, the specimen could be made to perform both conditions.

Moulds of $5 \mathrm{~cm}$ in diameter and $10 \mathrm{~cm}$ in height were filled up with the mixture. The top surface of the mould was sealed with wrap. These moulds were placed in a closed box in which the temperature and humidity were maintained at $20^{\circ} \mathrm{C}$ and $95 \%$ for about 28 days.

\section{Permeability Test}

Permeability tests were performed with triaxial apparatus made for the X-ray CT scanner. In a series of permeability tests, the specimens were consolidated under a $50 \mathrm{kPa}$ confining pressure for 3 days. And then, a back pressure of $20 \mathrm{kPa}$ was applied to the bottom of the specimens to create an overall hydraulic gradient of 20 . The influent and effluent water volumes were measured using volume change burettes. The specimens were scanned by the X-ray CT scanner several times during the permeability tests.

Figure 13 shows the relationship between time and the influent/effluent water volume in the triaxial permeability tests. Air in effluent fluid from top of the specimens was observed in the permeability tests on $0.8 \mathrm{~g} / \mathrm{cm}^{3}$ and 0.6 $\mathrm{g} / \mathrm{cm}^{3}$ target density specimens. The water volume in Fig. 13 included the effluent air, because the volume of air and water could not be separated in this triaxial apparatus. The influent water volume was almost equal to the effluent water volume in each test case. The effluent and influent water volumes both in $1.25 \mathrm{~g} / \mathrm{cm}^{3}$ and in 1.1 $\mathrm{g} / \mathrm{cm}^{3}$ target density cases were increased proportionally with time. But the effluent and influent water volume changes of $0.8 \mathrm{~g} / \mathrm{cm}^{3}$ target density specimen were large at the beginning of the test, and they were getting smaller with time. Table 4 concludes the density changes and the coefficient of permeability for each case. The coefficient of permeability in $0.8 \mathrm{~g} / \mathrm{cm}^{3}$ target density specimen was changed during the test and the coefficients presented in Table 4 were those measured in last stage of the tests. The permeability of the specimen with a target density of 1.1 $\mathrm{g} / \mathrm{cm}^{3}$ is smaller than that of the specimen without air foam whose target density was $1.25 \mathrm{~g} / \mathrm{cm}^{3}$. Both speci-

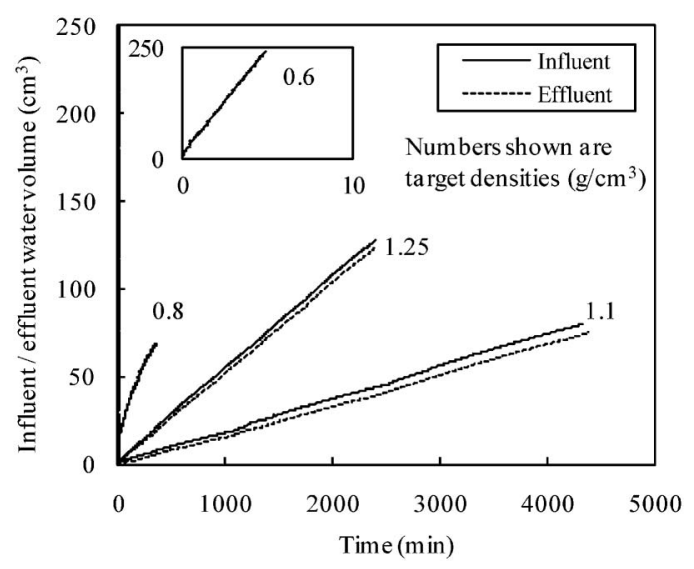

Fig. 13. Relationship between time and influent/effluent water volume

Table 3. Mixing condition for CTC and SGM

\begin{tabular}{c|c|c|c|c|c|c|c|c}
\hline \multirow{2}{*}{ Target density } & \multicolumn{2}{|c|}{$1.25 \mathrm{~g} / \mathrm{cm}^{3}$ (air 0\%) } & \multicolumn{2}{|c|}{$1.1 \mathrm{~g} / \mathrm{cm}^{3}$ (air 13\%) } & \multicolumn{2}{c|}{$0.8 \mathrm{~g} / \mathrm{cm}^{3}$ (air 38\%) } & \multicolumn{2}{c}{$0.6 \mathrm{~g} / \mathrm{cm}^{3}($ air $59 \%)$} \\
\cline { 2 - 11 } & Mass (kg) & Volume (L) & Mass (kg) & Volume (L) & Mass (kg) & Volume (L) & Mass (kg) & Volume (L) \\
\hline Dry mass & 283 & 103 & 246 & 89 & 152 & 55 & 94 & 34 \\
\hline Water & 904 & 878 & 787 & 764 & 560 & 544 & 347 & 337 \\
\hline Cement & 60 & 20 & 61 & 20 & 69 & 23 & 130 & 43 \\
\hline Air foam & - & - & 6 & 127 & 19 & 378 & 29 & 586 \\
\hline Total & 1247 & 1000 & 1100 & 1000 & 800 & 1000 & 600 & 1000 \\
\hline
\end{tabular}


mens with 0.8 and $0.6 \mathrm{~g} / \mathrm{cm}^{3}$ target densities had very high coefficients of permeability compared to that of the specimen without air foam.

The densities of the specimens with 0.8 and $0.6 \mathrm{~g} / \mathrm{cm}^{3}$ of target densities were increased after permeability tests. From the observation, air emerged from the specimens in the early stage of the permeability tests. It was thought that some part of the air foam was replaced by influent water and that the influent water could easily flow though the water-bleeding channels in these specimens. The densities of the specimens with 1.1 and $1.25 \mathrm{~g} / \mathrm{cm}^{3}$ target den-

Table 4. Density change and coefficient of permeability

\begin{tabular}{|c|c|c|c|}
\hline & \multicolumn{2}{|c|}{ Wet density $\left(\mathrm{g} / \mathrm{cm}^{3}\right)$} & \multirow{2}{*}{$\begin{array}{l}\text { Coefficient of } \\
\text { permeability } \\
(\mathrm{cm} / \mathrm{s})\end{array}$} \\
\hline & Befor test & After test & \\
\hline $1.25 \mathrm{~g} / \mathrm{cm}^{3}$ (air $0 \%$ ) & 1.232 & 1.229 & $1.47 \times 10^{-6}$ \\
\hline $1.1 \mathrm{~g} / \mathrm{cm}^{3}$ (air $13 \%$ ) & 1.114 & 1.122 & $8.33 \times 10^{-7}$ \\
\hline $0.8 \mathrm{~g} / \mathrm{cm}^{3}$ (air $38 \%$ ) & 0.816 & 0.894 & $3.47 \times 10^{-6}$ \\
\hline $0.6 \mathrm{~g} / \mathrm{cm}^{3}$ (air $59 \%$ ) & 0.676 & 0.951 & $1.87 \times 10^{-3}$ \\
\hline
\end{tabular}

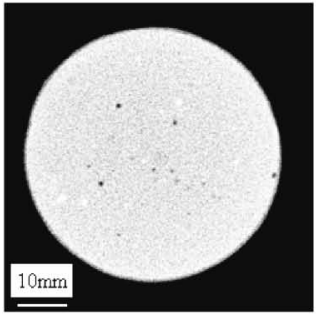

Initial

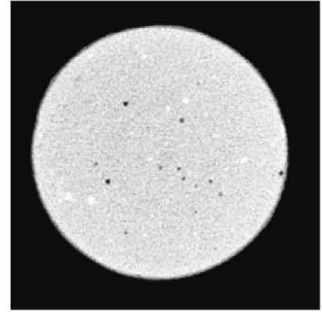

40 hours

(a) $1.25 \mathrm{~g} / \mathrm{cm}^{3}$ target density (CTC)

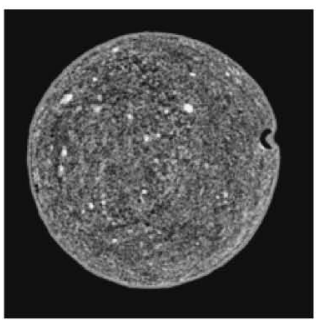

Initial

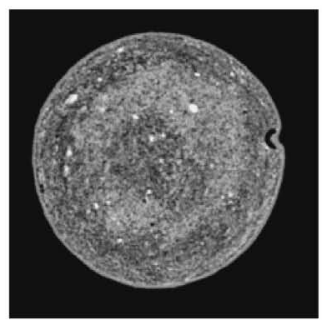

$3 \min$

(c) $0.8 \mathrm{~g} / \mathrm{cm}^{3}$ target density (SGM)

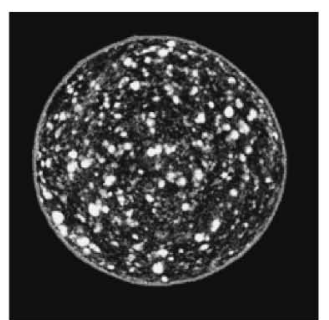

Initial

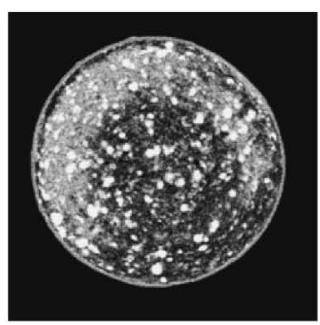

$30 \mathrm{sec}$

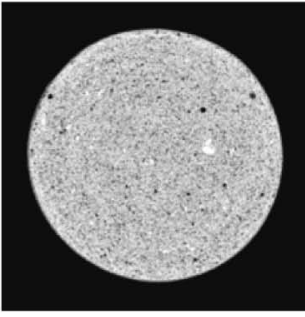

Initial

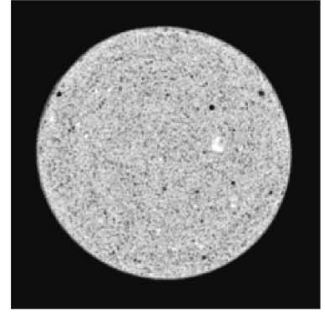

72 hours

(b) $1.1 \mathrm{~g} / \mathrm{cm}^{3}$ target density (SGM)

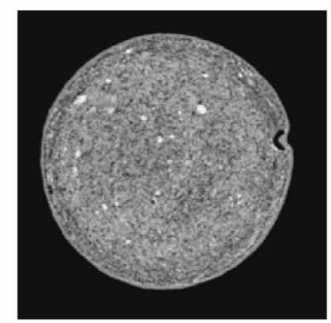

$30 \mathrm{~min}$

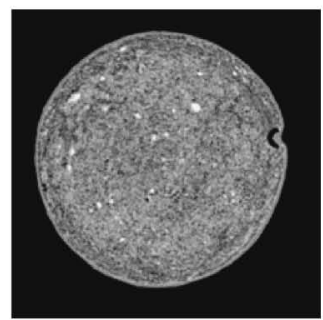

$300 \mathrm{~min}$

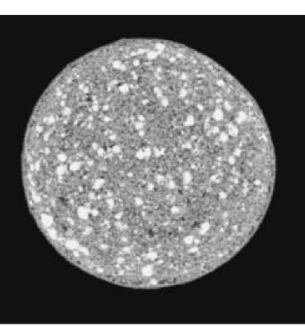

$60 \mathrm{sec}$

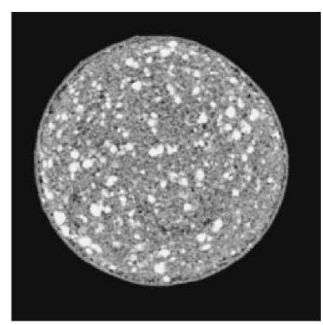

$300 \mathrm{sec}$

(d) $0.6 \mathrm{~g} / \mathrm{cm}^{3}$ target density (SGM)

Fig. 14. Cross-sectional CT images 


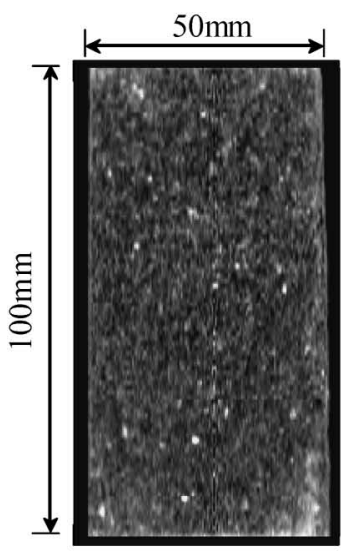

Initial

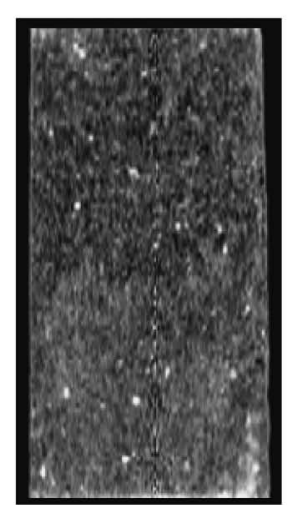

$3 \min$

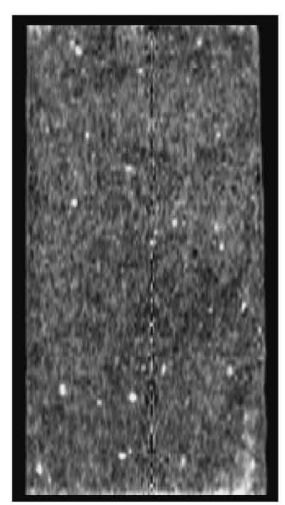

$30 \mathrm{~min}$

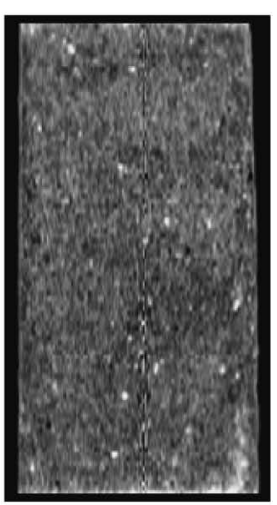

$300 \mathrm{~min}$

Fig. 15. Vertical cross-sectional CT images $\left(0.8 \mathrm{~g} / \mathrm{cm}^{3}\right.$ target density)

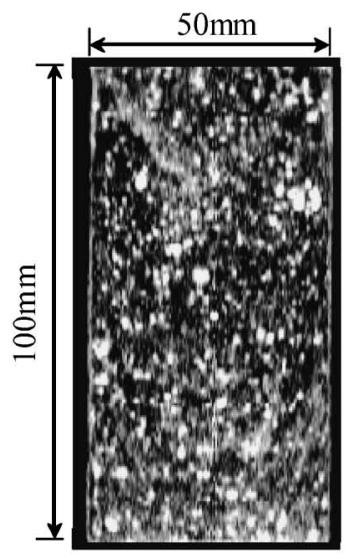

Initial

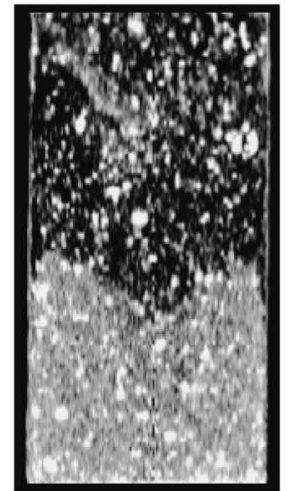

$30 \mathrm{sec}$

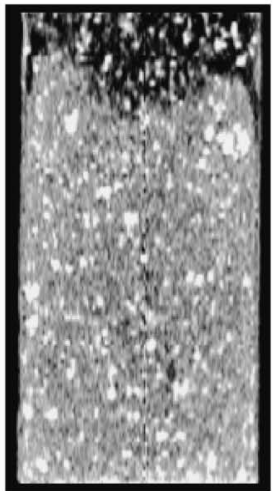

$60 \mathrm{sec}$

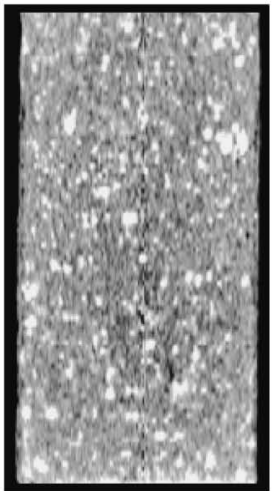

$300 \mathrm{sec}$

Fig. 16. Vertical cross-sectional CT images $\left(0.6 \mathrm{~g} / \mathrm{cm}^{3}\right.$ target density)

uniformly, but occurred randomly at the early stage of the tests. And at the end of the tests, the density became almost constant.

Figures 15 and 16 show the vertical cross section of the specimen during the permeability tests with 0.8 and 0.6 $\mathrm{g} / \mathrm{cm}^{3}$ target density specimens. These images show that density increments occurred from the bottom to the top of the specimen. And their density changes occurred at the early stage of the experiment. It was observed that the boundary of density change zone which represents the front of the zone of air exchanged to water was not parallel compared with the influent surface.

Figure 17 shows the density distribution from the initial condition to the end of the permeability test for 1.1, 0.8 and $0.6 \mathrm{~g} / \mathrm{cm}^{3}$ target densities evaluated by using the CT data of these specimens. The density distribution of $1.1 \mathrm{~g} / \mathrm{cm}^{3}$ target density did not change much at all. In contrast, the densities of specimen with 0.8 and $0.6 \mathrm{~g} / \mathrm{cm}^{3}$ target densities were increased during permeability tests. The main reason of the density changes during permeability tests were considered to be the substitution of air to the water, because the density change occurred in a short time and effluent of air from the specimen was observed in some specimens.

Figure 18 shows the calculated results of the water substitution ratio relative to the initial air volume. The water substitution ratio defined here was the ratio of substituted volume of air to initial volume of air. The initial air volume was evaluated from the initial wet density and the initial water content ratio. This calculation is based on two assumptions. First, the clay slurry with cement is assumed to be uniform in the specimen. This means that variances in density are attributable to variances in air volume. The second assumption is that density change is attributable to substitution of water for air.

Figure 18 shows that substitution of water for air occurred from the bottom to the top of the specimen; main substitution occurred in the early stage of permeability tests; substitution ratio was affected by the target density, and the substitution ratio was 0.6 even in the specimen 


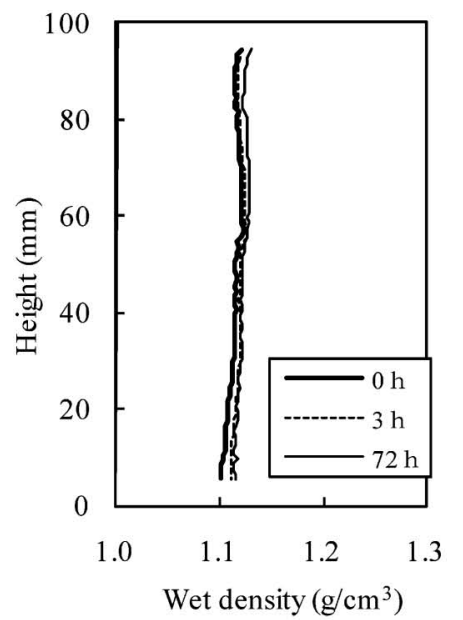

(a) $1.1 \mathrm{~g} / \mathrm{cm}^{3}$ target density

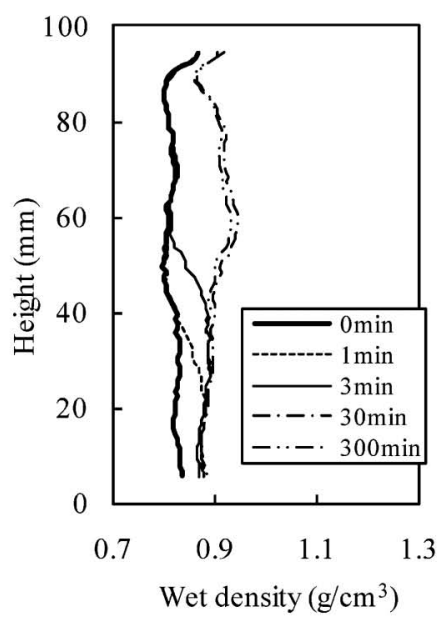

(b) $0.8 \mathrm{~g} / \mathrm{cm}^{3}$ target density

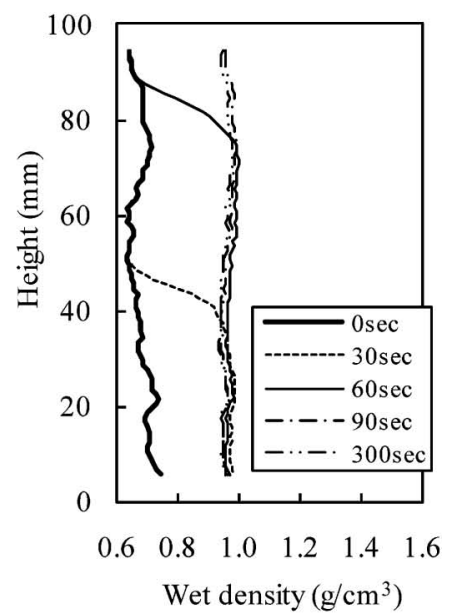

(c) $0.6 \mathrm{~g} / \mathrm{cm}^{3}$ target density

Fig. 17. Density distribution

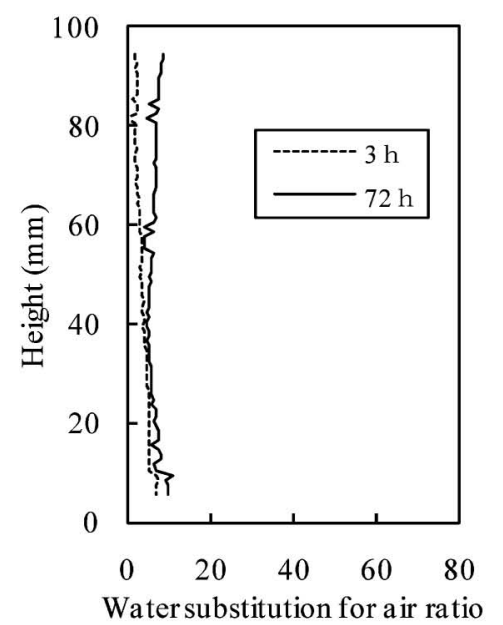

$(\%)$

(a) $1.1 \mathrm{~g} / \mathrm{cm}^{3}$ target density

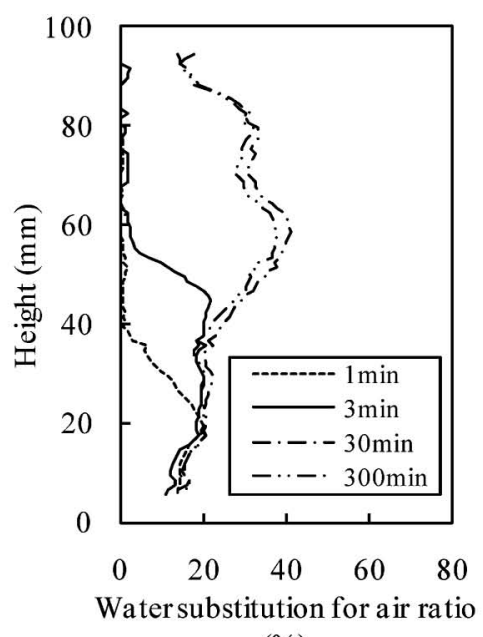

(\%)

(b) $0.8 \mathrm{~g} / \mathrm{cm}^{3}$ target density

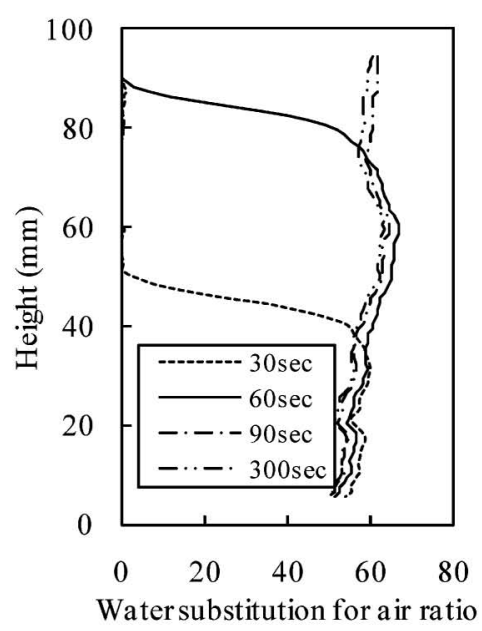

$(\%)$

(c) $0.6 \mathrm{~g} / \mathrm{cm}^{3}$ target density

Fig. 18. Water substitution for air ratio

with $0.6 \mathrm{~g} / \mathrm{cm}^{3}$ target density.

Figure 19 shows high-magnification images of the horizontal cross section of each specimen with $1.1,0.8$ and $0.6 \mathrm{~g} / \mathrm{cm}^{3}$ target densities. These images were chosen around middle height of each specimen. The images shown in the figure were taken both before and after permeability tests. Each image was not the same cross section, but is similar sections, because it was difficult to specify the cross section after the permeability test. The black circular parts in these images are air voids. There are small changes observed in the image of $1.1 \mathrm{~g} / \mathrm{cm}^{3}$ target density during permeability test. On the other hand, the images of 0.8 and $0.6 \mathrm{~g} / \mathrm{cm}^{3}$ target densities show the decrement of the black circular parts during permeability test, but not all of the black circular parts disappeared. As seen in Fig. 18, substitution of water for air occurred in a short time and it happened from the bottom to the upper part. Further the air that was not substituted in the early stage remained at the same position. The permeability of the each specimen except air void was considered to be a little different. From these observations and considerations, the high coefficients of permeability of the low target densities was mainly caused by the water flow in the void substituted to water from air. Thus, the water bleeding channels were constructed in most part of the voids substituted to water from air.

Figure 20 shows the change of coefficient of permeability of SGM according to the change of air fraction. The vertical axis of the figure is the coefficient of apparent permeability normalized by that of CTC. The points marked by in this figure are the results of test. The points marked by $\triangle$ is permeability test results shown in Fig. 9. The points marked by $\bigcirc$ and $\times$ are other test results (Watabe et al., 2005; Kikuchi and Nagatome, 
2007). The coefficients of permeability of SGM with about less than $25 \%$ air volume are lower than that of CTC. However, the coefficients of permeability of SGM with about more than $30 \%$ air volume are quite large

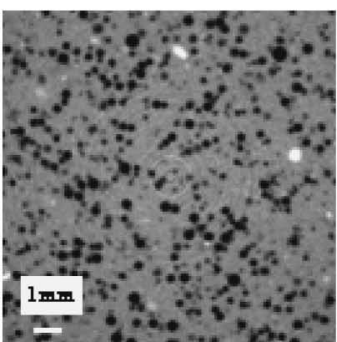

Initial

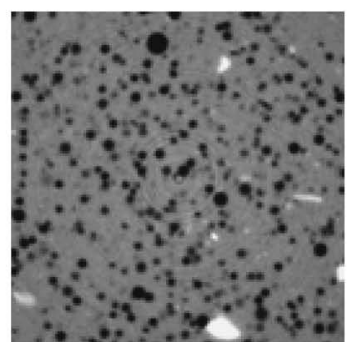

After test (a) $1.1 \mathrm{~g} / \mathrm{cm}^{3}$ target density

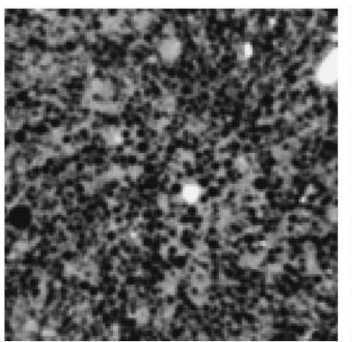

Initial

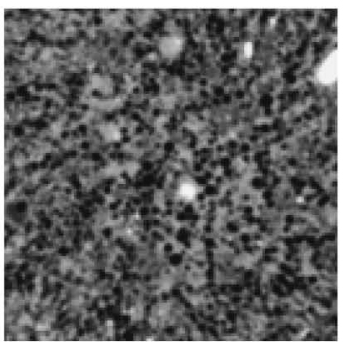

After test (b) $0.8 \mathrm{~g} / \mathrm{cm}^{3}$ target density

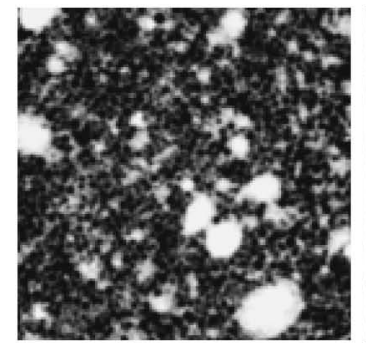

Initial

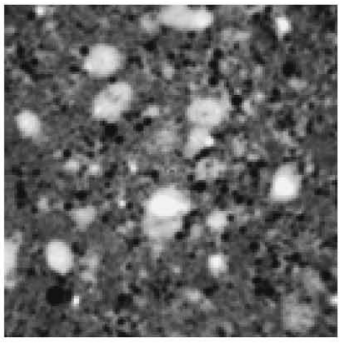

After test (c) $0.6 \mathrm{~g} / \mathrm{cm}^{3}$ target density

Fig. 19. High-magnification CT images of cross section

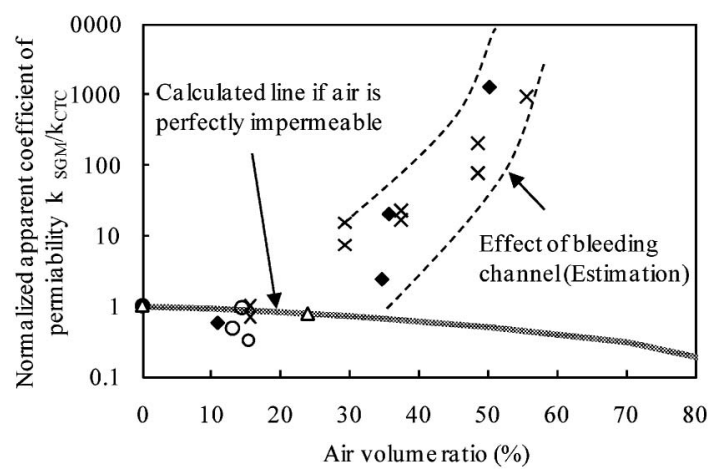

Fig. 20. Relationship between air volume ratio and apparent coefficient of permeability. The points of marked by $\bullet$ are the results of test. The points marked by $\triangle$ are permeability test results shown in Fig. 9. The points marked by $\bigcirc$ and $\times$ are other test results (Watabe et al., 2005; Kikuchi and Nagatome, 2007) compared to that of CTC. It is considered that this difference is due to water bleeding channels in the specimen.

These results show that water bleeding channels will tend to form if the air content is excessively large, so the wet density and coefficient of permeability will tend to increase. On the other hand, when the air content is small, the air functions as an impermeable medium.

\section{ABSORPTION TEST WITH X-RAY CT SCANNER}

An absorption test was performed with the specimens for the target densities of $1.25,1.1,0.8$ and $0.6 \mathrm{~g} / \mathrm{cm}^{3}$, respectively as shown in Table 3 . The specimen was soaked in water at a constant temperature of $20^{\circ} \mathrm{C}$ as shown in Fig. 21. In this experiment, the water could be absorbed into the specimen not only from the side surface, but also from the bottom surface and top surface. The weight and volume of each specimen were measured, and specimen was scanned by an X-ray CT scanner over prescribed elapsed periods. This test was continued for 282 days.

Figure 22 shows the relationship between the wet density and elapsed days of each specimen. It was found that the density of each specimen of SGM was increased with the increment of elapsed days. The density of the specimen with $0.6 \mathrm{~g} / \mathrm{cm}^{3}$ target density was dramatically increased in the first day of elapsed day. And in this case,

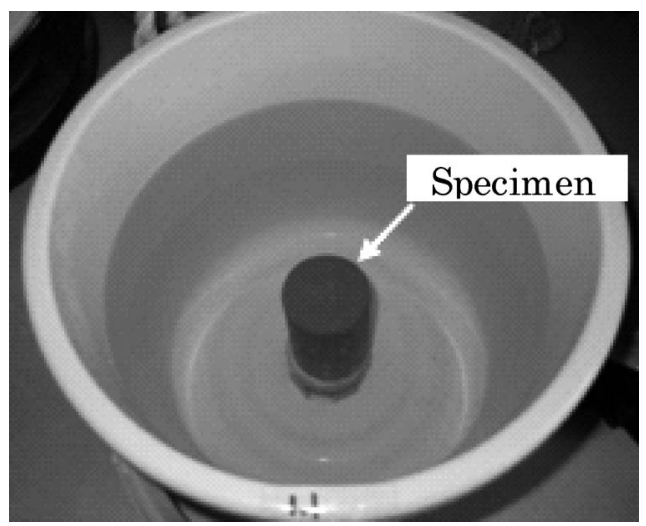

Fig. 21. Photograph of absorption test

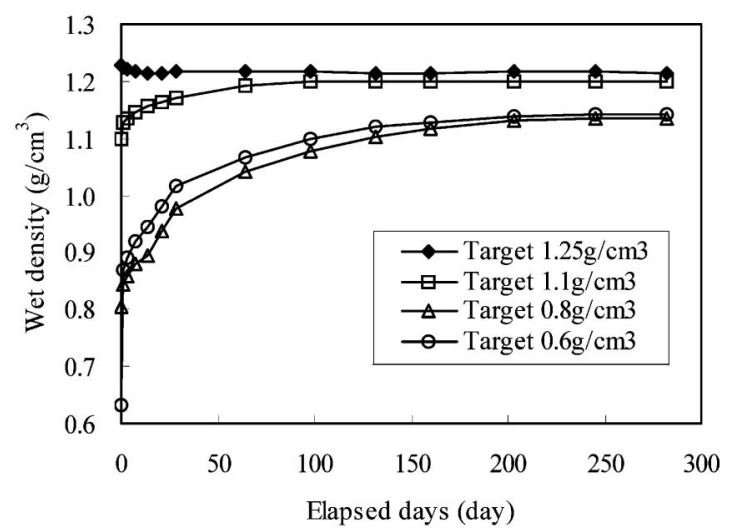

Fig. 22. Relationship between wet density and elapsed days 


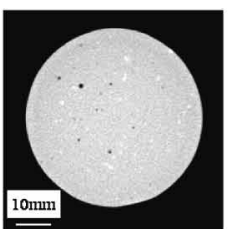

Initial

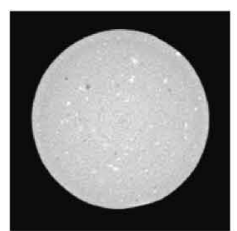

28 day

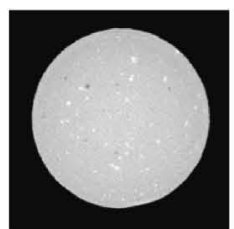

98 days

(a) $1.25 \mathrm{~g} / \mathrm{cm}^{3}$ target density

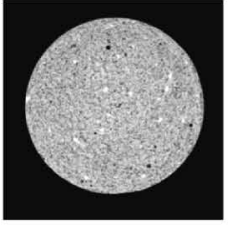

Initial

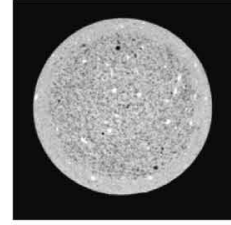

7 days

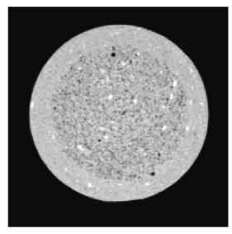

14 days

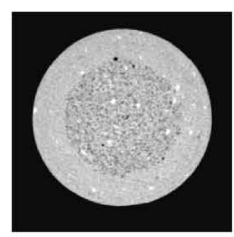

28 days

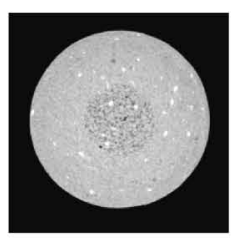

64 days

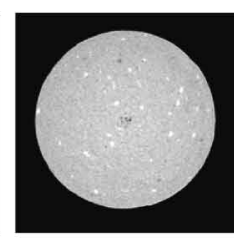

98 days

(b) $1.1 \mathrm{~g} / \mathrm{cm}^{3}$ target density

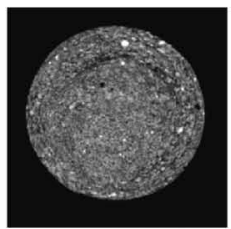

Initial

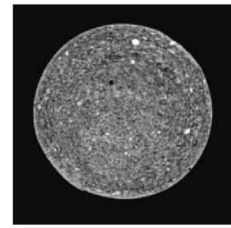

7 days

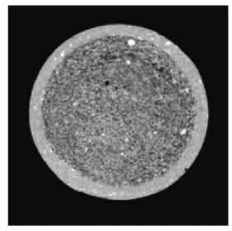

28 days

(c) $0.8 \mathrm{~g} / \mathrm{cm}^{3}$ target density

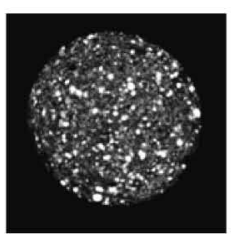

Initial

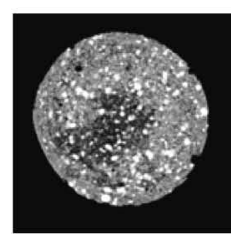

1 day

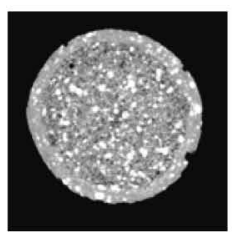

28 days

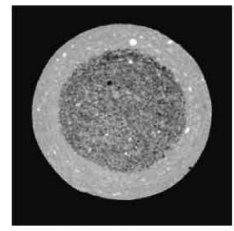

64 days

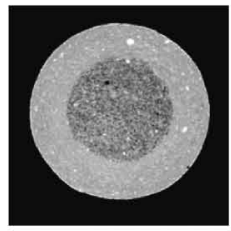

98 days

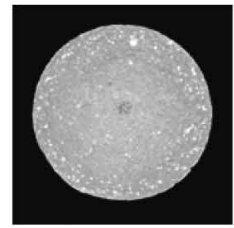

282 days

(d) $0.6 \mathrm{~g} / \mathrm{cm}^{3}$ target density

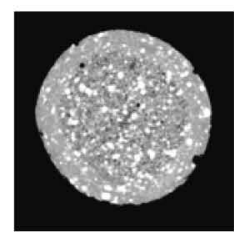

64 days

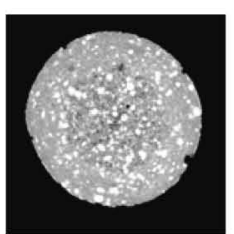

98 days

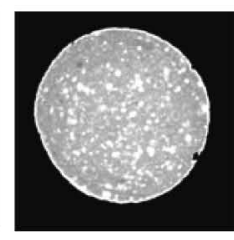

282 days

Fig. 23. Cross-sectional CT image

bubbles came out from the specimen were observed. In such a meaning, large density change observed in the specimen with $0.6 \mathrm{~g} / \mathrm{cm}^{3}$ target density in the first elapsed day was not absorption. In contrast, the density of CTC showed no large change.

Figure 23 shows cross-sectional images of each specimen during the absorption test. These images were chosen at the middle height of each specimen. The images of CTC showed no large change. Meanwhile, the images of SGM showed extended lighter parts from the water contact surface to the inside of the specimen with elapsed time. These lighter parts were absorbed zones. It was observed that the absorbed zone was extended gradually into inside in a concentric circle for the target densities of 1.1 and $0.8 \mathrm{~g} / \mathrm{cm}^{3}$. In the case of the specimen with 0.6 $\mathrm{g} / \mathrm{cm}^{3}$ target density, clear substitution of water for air was observed during the early stage of the elapse. Except for this phenomenon, the lighter concentric circle was expanded into inside from the surface similar to other target density SGM specimens. Comparing the thickness of the concentric circular light zone, the specimen with 1.1 $\mathrm{g} / \mathrm{cm}^{3}$ target density had the thickest and specimens with 0.8 and $0.6 \mathrm{~g} / \mathrm{cm}^{3}$ target density had similar thickness.

Figure 24 shows the vertical cross section of the specimen of the same experiment. Expansions of lighter part from the surface to inside with time were observed from 


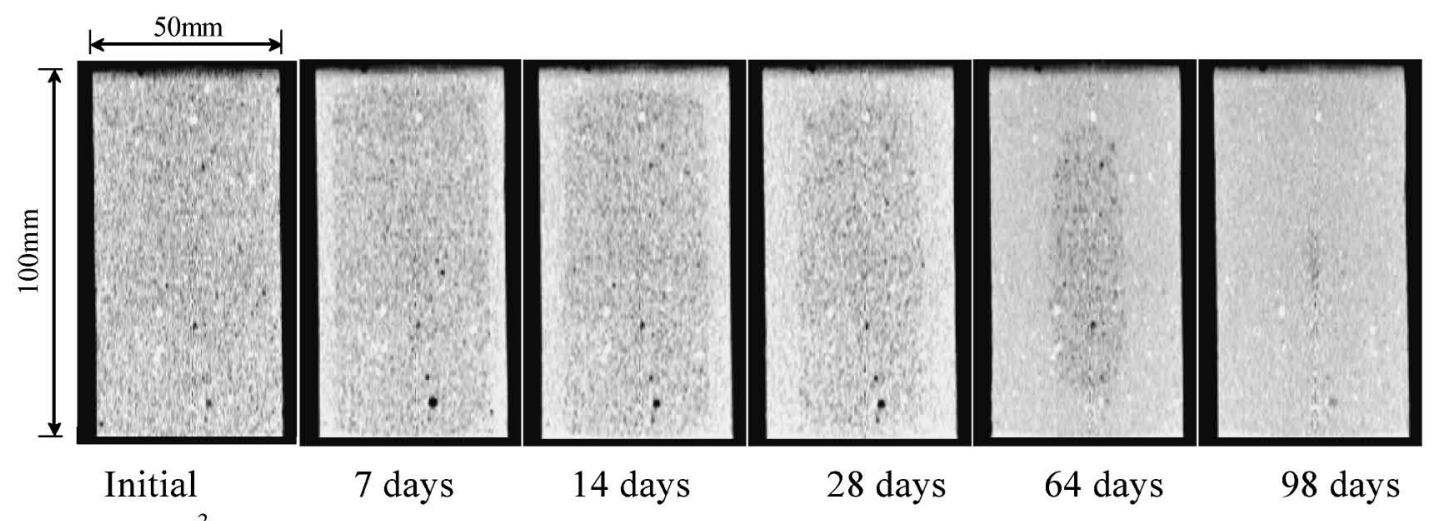

(a) $1.1 \mathrm{~g} / \mathrm{cm}^{3}$ target density

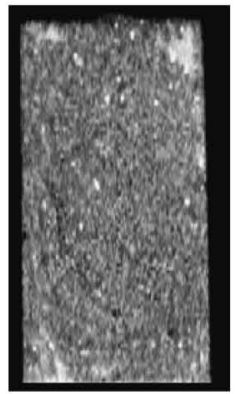

Initial

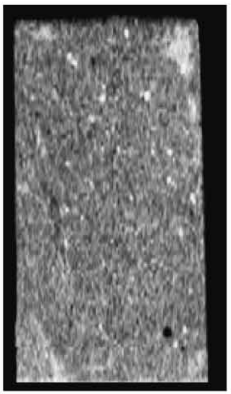

7 days

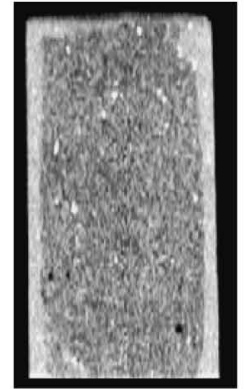

28 days

(b) $0.8 \mathrm{~g} / \mathrm{cm}^{3}$ target density

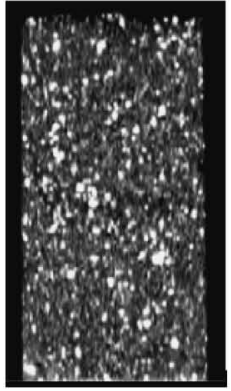

Initial

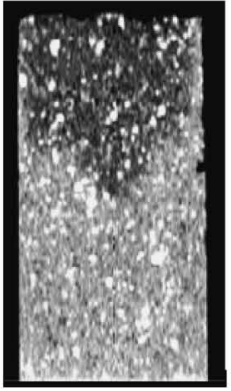

1 day

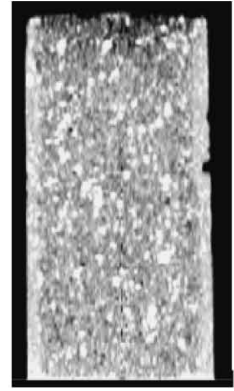

28 days

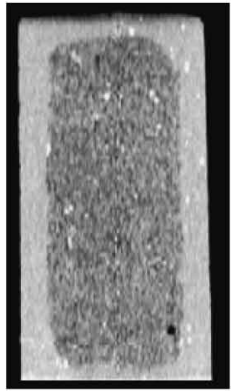

64 days

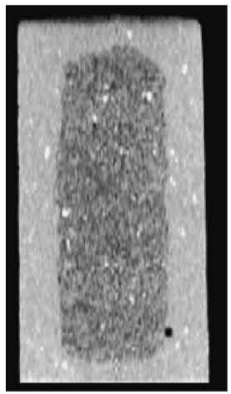

98 days

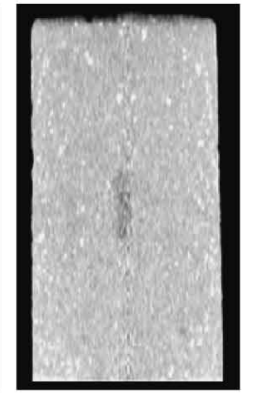

282 days

(c) $0.6 \mathrm{~g} / \mathrm{cm}^{3}$ target density

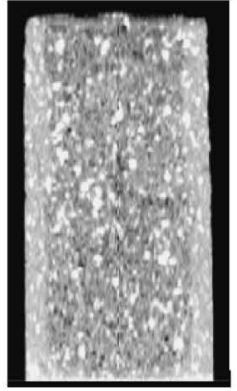

64 days

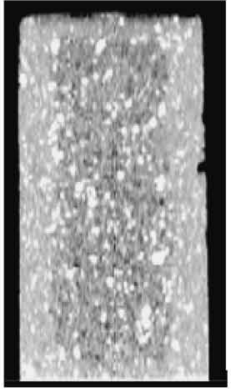

98 days

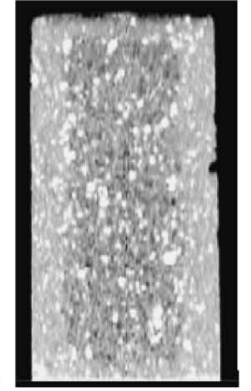

282 days

Fig. 24. Vertical cross-sectional CT image

the images as similar to Fig. 23.

Figure 25 shows the image of the whole cross section and the high magnified cross section during the absorption experiment. This figure shows that the absorption occurred from the surface. As shown in Fig. 25, no air voids were observed in the ring shaped lighter part and all the air voids inner than this part remained. It means that there was distinct boundary between absorbed zone and non absorbed zone and the front of the absorbed zone could be defined.

Figure 26 shows the change of the distribution of density along the radial direction of cross-sectional area at around middle height of each specimen. The density was evaluated from GL values. Saturated densities calculated from measured density and mixing condition were presented in these figures. Figure 26(a) shows the result of the case of the $1.1 \mathrm{~g} / \mathrm{cm}^{3}$ target density specimen. In this figure, the density increased from the water contact surface to the central part of the specimen. In about 100 days, most part of the specimen was saturated. In the case of the specimen with $0.8 \mathrm{~g} / \mathrm{cm}^{3}$ target density, the increment of the density also observed from the surface to the inside in Fig. 26(b), but central part of the specimen remained unsaturated in 98 days of curing. It means that the velocity of absorbed zone expansion was smaller in the specimen with $0.8 \mathrm{~g} / \mathrm{cm}^{3}$ target density than in the specimen with $1.1 \mathrm{~g} / \mathrm{cm}^{3}$ target density. Figure $26(\mathrm{c})$ shows the results with $0.6 \mathrm{~g} / \mathrm{cm}^{3}$ target density specimen. As seen in Fig. 23 or 24, clear water channel was observed and the substitution of water for air occurred in the be- 


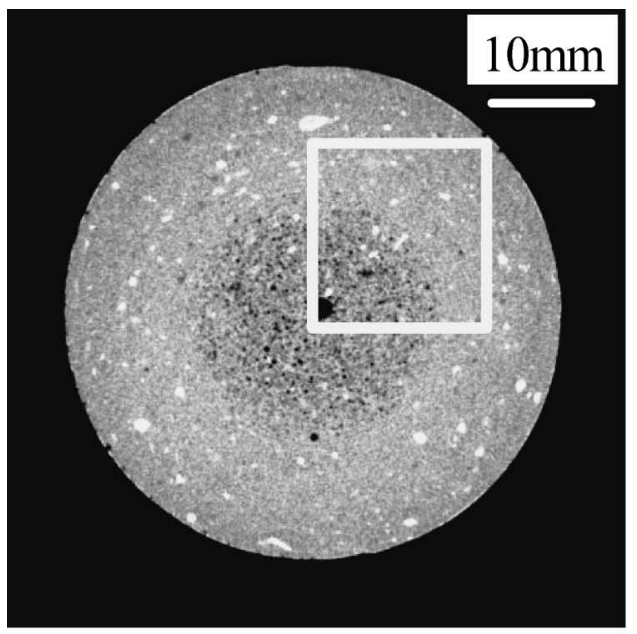

(a) Whole

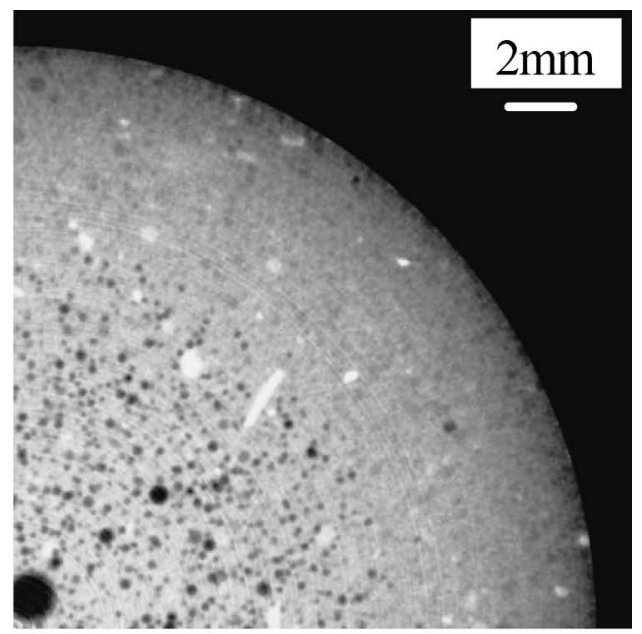

(b) High magnification

Fig. 25. Whole and high magnification images in absorption test

ginning of the absorption experiment. Because of this phenomenon, wet density increment was observed in the specimen. This substitution made observation of the absorption from the surface difficult. But density increment of the specimen from the surface to inside was also observed. For example, density at $20 \mathrm{~mm}$ to $25 \mathrm{~mm}$ was increased between 1 day to 28 days. The density at $17 \mathrm{~mm}$ to $22 \mathrm{~mm}$ was increased between 28 day to 64 days. Similar density change was observed in each observation step. Finally, density change from 1 day was found up to around $13 \mathrm{~mm}$ of the radius. This value was almost the same as the specimen with $0.8 \mathrm{~g} / \mathrm{cm}^{3}$ target density. In the density increased area, the density was almost saturated density. So it was considered that most air foams in these specimens were replaced by water.

Figure 27 shows the relationship between the absorbed distance from the surface and the elapsed days. Here, absorbed distance was defined as the thickness of the lighter part of the concentric zone and this zone was considered as zone where air foams were almost replaced by water. And the absorbed distance was calculated using the crosssectional X-ray CT data. The absorbed zone expanding velocity of each specimen was almost constant irrespective of the number of elapsed days. And the absorbed zone expanding velocity of the specimen with $1.1 \mathrm{~g} / \mathrm{cm}^{3}$ target density was higher than those of the specimen with 0.8 and $0.6 \mathrm{~g} / \mathrm{cm}^{3}$ target densities. It means absorbed zone expanding velocity is irrespective to permeability.

Figure 28 shows the relationship between the elapsed days and air foam volume of each specimen. Air foam volumes calculated in this figure were from the density of each specimen during absorption test. Initial air volume of each specimen was different, because the target density was different. But because of the effect of water bleeding channel, air volume change of the specimens with 0.6 and $0.8 \mathrm{~g} / \mathrm{cm}^{3}$ target densities were similar in this test. It is an interesting correspondance that air void volume of specimen with 0.6 and $0.8 \mathrm{~g} / \mathrm{cm}^{3}$ target density are similar, and their absorption zone expansion velocities were nearly equal. And the specimen with $1.1 \mathrm{~g} / \mathrm{cm}^{3}$ target density had less air volume and the velocity was fastest. From this observation absorbed zone expanding velocity may be governed not by the overall permeability but by the amount of initial air volume.

\section{CONCLUSION}

In this paper, permeation and absorption mechanisms of cement treated clay with air foam (SGM) were discussed. In this research, permeability tests and absorption tests were conducted for SGM with different ratios of air foam in volume. The main conclusions are as follows:

1) The air voids in the material are an impermeable compressible medium when fraction of the air voids was less than $30 \%$.

2) Air foam works as the water bleeding channels by making a string hole and the coefficient of permeability increased dramatically when the fraction of air foam is larger than $30 \%$.

3) The air in SGM was substituted to water from the surface to inside in order. The absorption velocity of SGM is not governed by permeability but it may be governed by the amount of air volume.

\section{REFERENCES}

1) Desrues, J., Viggiani, G. and Besuelle, P. (2006): Advances in $X$ ray Tomography for Geomaterials, ISTE.

2) Kikuchi, Y. and Yoshino, H. (1998): Permeability of light-weight soil made of dredged slurry mixed with air foam, Report of Port and Harbour Research Institute, 37(1), 33-56 (in Japanese).

3) Kikuchi, Y. (2006): Engineering properties investigation of manmade composite geo-materials with micro X-ray CT, Advances in $X$-ray Tomography for Geomaterials, ISTE, 53-78.

4) Kikuchi, Y., Mizutani, T., Nagatome, T. and Hata, T. (2006): Study on applicability of micro-focus X-ray CT scanner for geomaterials, Technical Note of the Port and Airport Research Institute, (1125), 5-13 (in Japanese).

5) Kikuchi, Y. and Nagatome, T. (2007): Effects of air foam in lightweight soil to the permeability property, Proc. 7th National Sympo- 


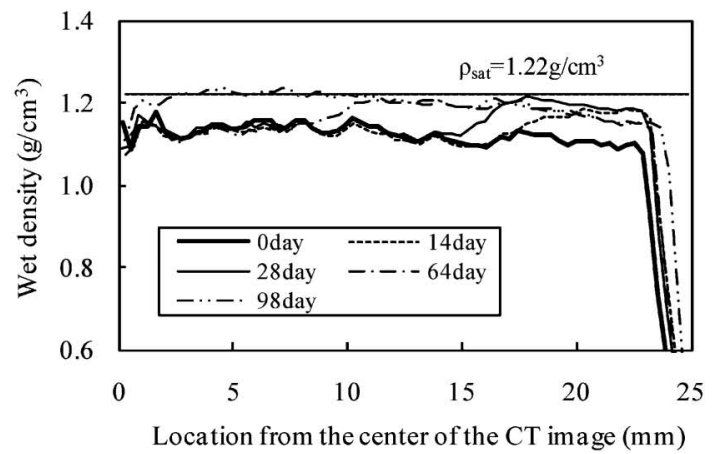

(a) $1.1 \mathrm{~g} / \mathrm{cm}^{3}$ target density

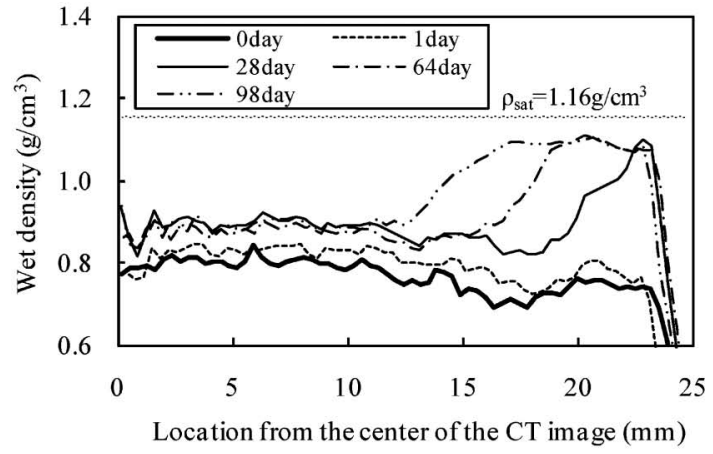

(b) $0.8 \mathrm{~g} / \mathrm{cm}^{3}$ target density

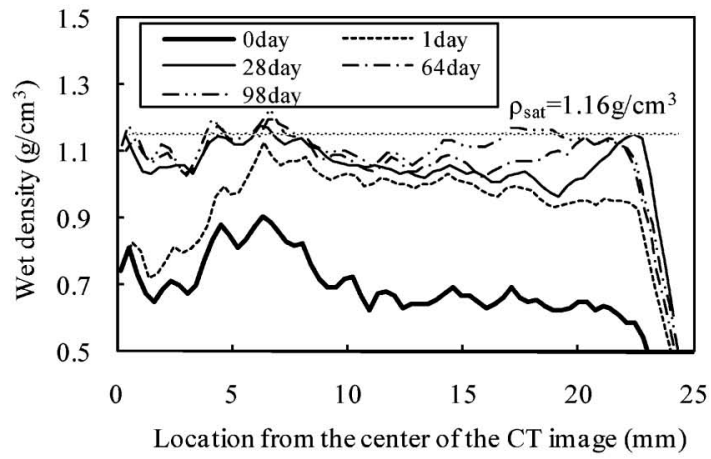

(c) $0.6 \mathrm{~g} / \mathrm{cm}^{3}$ target density

Fig. 26. Change of density distribution

sium on Environmental Geotechnology, 303-306 (in Japanese).

6) Kobayashi, M., Mizukami, J. and Tsuchida, T. (1990): Determination of the horizontal coefficient of consolidation $c_{\mathrm{h}}$, Report of Port and Harbour Research Institute, 29(2), 63-83 (in Japanese).

7) Mori, M., Inoue, S., Ishigure, Y., Funazu, E., Watanabe, N. and Kuroshima, I. (1994): Properties of air foamed soil cement-Part 8 permeability of saturated soils, Proc. 29th Japan National Conference on Geotechnical Engineering, 3, 2423-2424 (in Japanese).

8) Otani, J., Mukunoki, T., Nagatome, T., Kukuchi, Y. and Sato, T. (2002a): Characterization of seepage and drying on light weight soil with air foam using X-ray CT method, Journal of Geotechnical Engineering, JSCE, (701/III-58), 293-302 (in Japanese).

9) Otani, J., Mukunoki, T. and Kukuchi, Y. (2002b): Visualization for engineering property of in-situ light weight soils with air foams, Soils and Foundations, 42(3), 93-105.

10) Otani, J. and Obara, Y. (2004): X-ray CT for Geomaterials

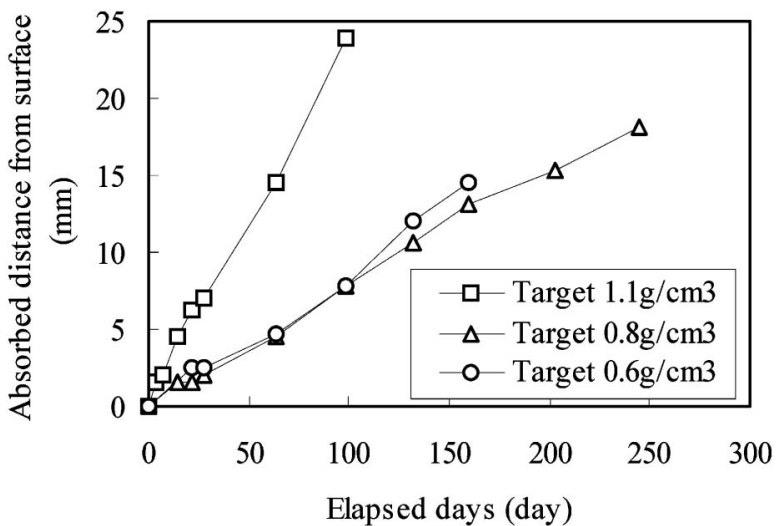

Fig. 27. Relationship between elapsed days and absorbed distance from the surface

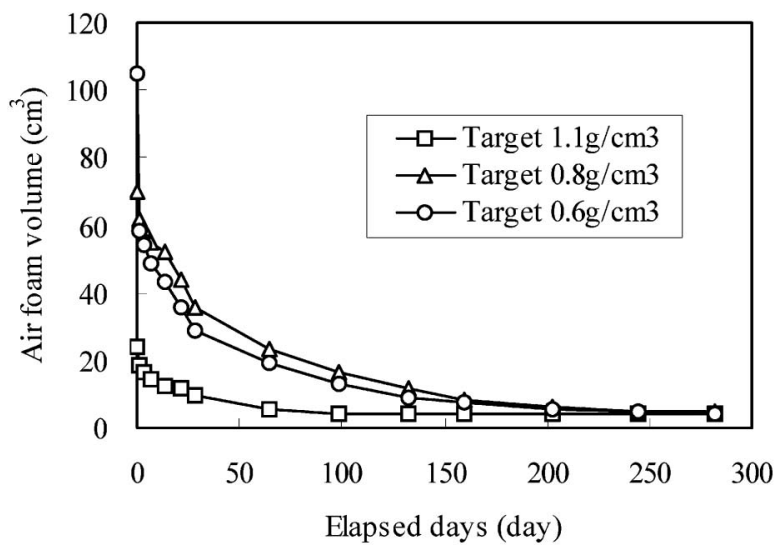

Fig. 28. Relationship between elapsed days and air foam volume

-GeoX2003_, Balkema.

11) Tani, K. and Ueda, K. (1993): Strike-slip fault model tests using Xray CT, Proc. 48th Japan Society of Civil Engineers Conference, III, 1408-1409 (in Japanese).

12) Tani, K. and Oyama, Y. (2004): Analysis of shear band structure developed in sand layer observed in strike-slip fault model tests, Journal of Geotechnical Engineering, JSCE, (757/III-66), 235-246 (in Japanese).

13) Terashi, M., Tanaka, H., Mitsumoto, T., Honda, S. and Ohashi, T. (1983): Fundamental properties of lime and cement treated soils (3rd Report), Report of Port and Harbour Research Institute, 22(1), 69-96 (in Japanese)

14) Tsuchida, T., Takeuchi, D., Okumura, T. and Kishida, T. (1996): Development of light-weight fill from dredgings, Environmental Geotechnics, Proc. 2nd International Congress on Environmental Geotechnics, Balkema, 415-420.

15) Verruijt, A. (1969): Elastic storage of aquifers, Flow through Porous Media, Academic Press, 331-374.

16) Watabe, Y., Watanabe, M., Shiina, T. and Okubo, Y. (2005): Hydraulic conductivity of air-foam treated light-weight soil in a microscopic point of view, Proc. 40th Japan National Conference on Geotechnical Engineering, 1, 831-832 (in Japanese).

17) Zen, K. (1993): Study on the wave-induced liquefaction in seabed, Technical Note of the Port and Harbour Research Institute, (755), 17-31 (in Japanese). 